[Agr. Biol. Chem., Vol. 36, No. 4, p. 544 550, 1972]

\title{
Studies on the Polysaccharides from Soy Sauce
}

\section{Part I. Purification and Properties of Two Acidic Polysaccharides}

\author{
By Tadaaki KIkUCHI and Tamotsu YokotsukA \\ Central Research Laboratories, Kikkoman Shoyu Co., Ltd. \\ Noda-shi, Chiba-ken, Japan \\ Received July 28, 1971
}

\begin{abstract}
Two water-soluble acidic polysaccharides were isolated and purified from soy sauce and their physico-chemical properties were investigated. The purified preparations seemed to be homogeneous on ultra-centrifugation and also on zone electrophoresis. Their sedimentation coefficients were $6.35 \mathrm{~S}$ and $1.9 \mathrm{~S}$, and their intrinsic viscosities were 0.47 and $0.11 \mathrm{dl} / \mathrm{g}$, respectively. Molecular weights were estimated to be 320,000 and 16,000 by gel filtration technique. Consequently, it was proved that these acidic polysaccharides were close in their sugar compositions to those prepared from soybean cell wall by the enzymatic decomposition. Therefore, these acidic polysaccharides in soy sauce were presumed to be originated from soybean cell wall
\end{abstract}

The authors have studied on cell wall polysaccharides in the soybean which is one of the main raw materials for soy sauce and reported about properties and enzymatic degradation of the cell wall polysaccharides. ${ }^{11}$ In the previous papers, they demonstrated that one of the major polysaccharides in soybean cell wall contained a large amount of galacturonic acid and was hardly hydrolyzed by an enzyme preparation from Aspergillus sojae X-816. Even after the enzymatic incubation, it still remained in the mixture as a water-soluble polymer. This fact suggested that some acidic polysaccharides must exist also in soy sauce itself.

Though there were reports about sugars contained in soy sauce, very little knowledge of high molecular polysaccharides in it has been obtained." Therefore, for food-chemical studies of soy sauce, it should be significant to investigate the physical and chemical properties of the polysaccharides in soy sauce. In this paper, the purification and some physico-chemical properties of acidic polysac- charides from soy sauce are described and discussed.

\section{MATERIALS AND METHODS}

Preparation of crude polysaccharides from soy sauce. Six liters of soy sauce brewed by Kikkoman Shoyu Co., Ltd. were mixed with an equal volume of ethanol, and the mixture was agitated and allowed to stand overnight. The precipitate was collected from the mixture by decantation and subsequent centrifugation, washed with $50 \%$ ethanol, dialysed against distilled water and freeze-dried. By means of these processes, $28 \mathrm{~g}$ of crude polysaccharide preparation was obtained.

Soybean cell wall. Soybean cell wall was prepared. by the same method as reported previously. ${ }^{11}$

Standard dextrans. Dextrans obtained from Pharmacia Co. were used as the standard samples for the examination of homogeneity and determination of molecular weight of the polysaccharides.

Chromatographic separation. DEAE-Cellulose (Brown) was employed for ion exchange chromatography with phosphate buffer ( $\mathrm{pH}$ 6.0). Sephadex G-200 and Sepharose $4 \mathrm{~B}$ (Pharmacia) equilibrated with $0.2 \mathrm{M}$ 
sodium chloride were used for gel filtration. Paper chromatography of monosaccharides was performed on Toyo No. 5lA paper with the developers, ethyl acetate-pyridine-water $(8: 2: 1 \text {, by vol. })^{31}$ or ethyl acetate-acetic acid-formic acid-water $(18: 3: 1: 4$, by vol.). ${ }^{4}$ The sugars were detected by the aniline hydrogen phthalate reagent. ${ }^{5}$ Polysaccharides were hydrolysed by $\mathrm{N}$ sulfuric acid at $100^{\circ} \mathrm{C}$ for $6 \mathrm{hr}$ and the hydrolysates were neutralized with barium carbonate and Dowex 50W.11

Zone electrophoresis. Electrophoresis was carried out on Whatman GF 81 glass fiber paper. ${ }^{\star}$ Pyridineacetic acid buffer ( $\mathrm{pH}$ 6.5) or sodium tetraborate buffer ( $\mathrm{pH} \mathrm{9.2)} \mathrm{were} \mathrm{used,} \mathrm{and} \mathrm{electrophoresis} \mathrm{zones}$ were located by the sulfonated 1-naphthol reagent.

Physical analysis. Sedimentation analysis was performed with a HITACHI UCA-1 at 55,430 rpm. Routine assays were carried out in $0.2 \mathrm{M}$ sodium chloride solution at $20^{\circ} \mathrm{C}$. The viscosity was estimated with an Ostwald's viscometer at $25^{\circ} \mathrm{C}$ and the partial specific volume was measured with a pair of pycnometers at $25^{\circ} \mathrm{C}$.

Estimation of molecular weight by gel filtration. One milligram of each of polysaccharide sample and of standard dextrans dissolved in $0.5 \mathrm{ml}$ of $0.2 \mathrm{M}$ sodium chloride was chromatographed on a Sephadex G-200 or a Sepharose $4 \mathrm{~B}$ column $(1.5 \times 90 \mathrm{~cm})$ with the same sodium chloride solution. $K d$ value was calculated from the elution pattern developed by phenol sulfate method. The molecular weights were estimated by Andrews' method.6)

Calculation of molecular weight. Another method used for the determination of the molecular weights of polysaccharides was that of Scheraga and Mandelkern.7) The molecular weight was calculated by

$$
M=4690 \cdot\left[s_{20, w}^{0}\right]^{3 / 2} \cdot[\gamma]^{1 / 2} /(1-\bar{V} \rho)^{3 / 2}
$$

where $M=$ molecular weight; $\left[s_{20}^{0}, \mathrm{w}\right]=$ sedimentation coefficient; $[\eta]=$ intrinsic viscosity; $\bar{V}=$ partial specific volume; and $\rho=$ density of medium.

Chemical analysis. The phenol-sulfuric acid method according to Dubois et al, ${ }^{8}$ was used for developing the elution patterns of polysaccharides. Uronic acid, pentose, and methylpentose were assayed by the carbazole method,9) phloroglucinol method,101 and cysteine-sulfuric acid method," respectively. Estima- tion of the esterified methoxyl residue was carried out by means of the modified Hatanaka's method. ${ }^{12}$

\section{RESULT}

\section{Purification of acidic polysaccharides}

Ten grams of crude polysaccharide preparation obtained from soy sauce were dissolved in $40 \mathrm{ml}$ of $0.02 \mathrm{M}$ phosphate buffer ( $\mathrm{pH} 6.0$ ), and insoluble materials were eliminated by centrifugation. The clarified polysaccharide solution was applied to a DEAE-cellulose column $(5 \times 75 \mathrm{~cm})$, and eluted by $0.02 \mathrm{M}$ and $0.5 \mathrm{M}$ buffer stepwise. Each fraction was dialysed against distilled water and freezedried, and $1.46 \mathrm{~g}$ of neutral polysaccharides (first fraction) and $4.44 \mathrm{~g}$ of acidic polysaccharides (APS: second fraction) were obtained.

Subsequently, $500 \mathrm{mg}$ of crude APS was dissolved in $10 \mathrm{ml}$ of $0.2 \mathrm{M}$ sodium chloride and subjected to gel filtration on Sephadex G-200. Two peaks were revealed by plotting

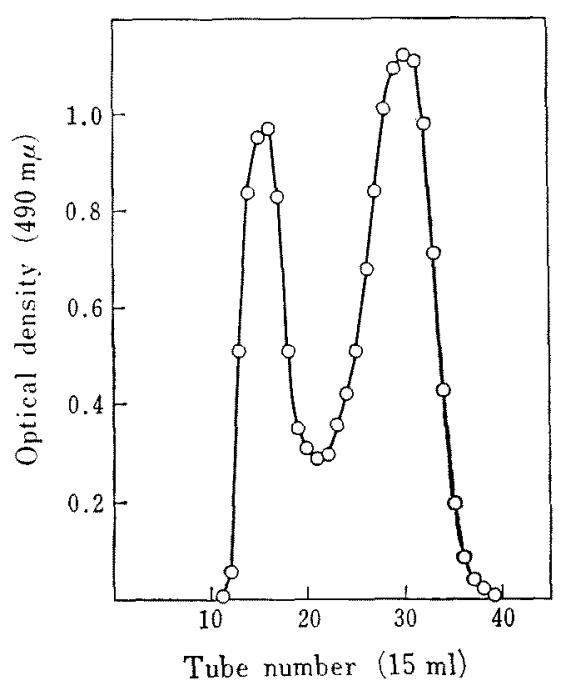

Fig. 1. Gel Filtration of Crude Acidic Polysaccharides on Sephadex $\mathrm{G}-200$.

Five hundred $\mathrm{mg}$ of polysaccharides were dissolved in $10 \mathrm{ml}$ of $0.2 \mathrm{M} \mathrm{NaCl}$ and applied on the column $(2.5 \times 110 \mathrm{~cm})$. Elution was performed with $0.2 \mathrm{M} \mathrm{NaCl}$ at $5^{\circ} \mathrm{C}$. 


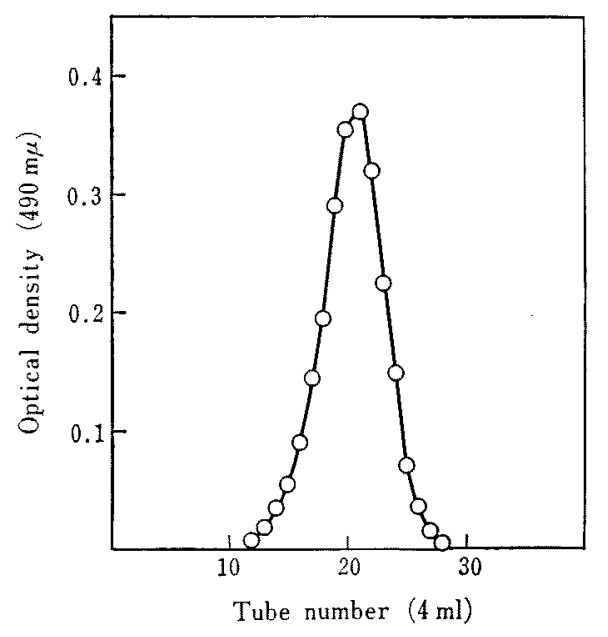

FIG. 2. Elution Pattern of APS-I from the Sepharose 4B Column.

One $\mathrm{ml}$ of $0.1 \%$ polysaccharide solution was applied on the column $(1.5 \times 90 \mathrm{~cm})$. Elution was performed with $0.2 \mathrm{M} \mathrm{NaCl}$.

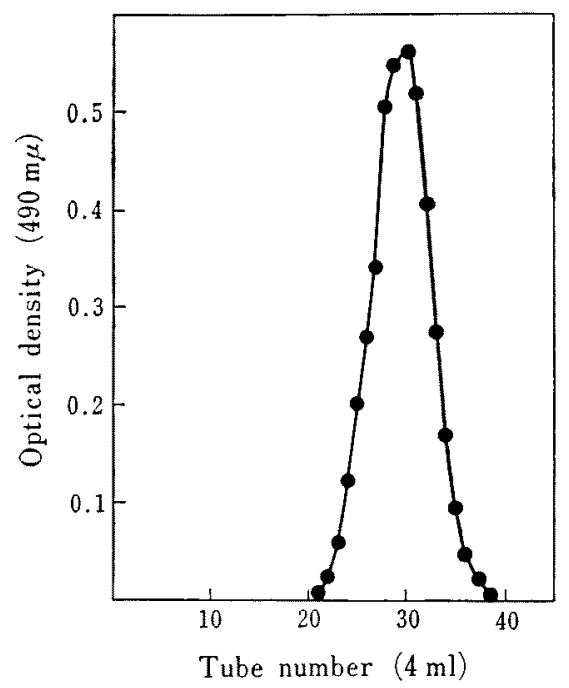

FIg. 3. Elution Pattern of APS-II from the Sephadex G-200 Column.

One $\mathrm{ml}$ of $0.2 \%$ polysaccharide solution was applied on the column $(1.5 \times 90 \mathrm{~cm})$. Elution was performed with $0.2 \mathrm{M} \mathrm{NaCl}$.

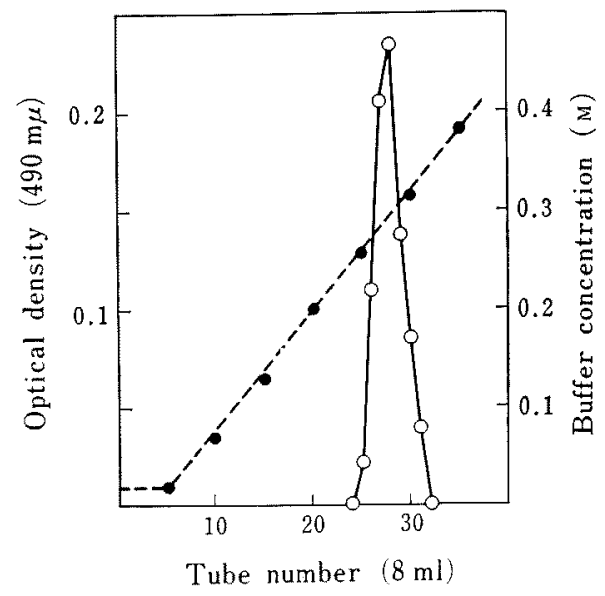

FIG. 4. Ion Exchange Chromatography of APS-I on DEAE-Cellulose.

Gradient elution was carried out with phosphate buffer $(\mathrm{pH}$ 6.0), Column: $1 \times 28 \mathrm{~cm}$.

carbohydrate concentrations in the effluents (Fig. 1). Each peak fraction was dialysed and freeze-dried, and $161 \mathrm{mg}$ of a high molecular fraction (APS-I) and $251 \mathrm{mg}$ of a low molecular fraction (APS-II) were obtained.

Examination of homogeneity of APS-I and $-I I$

Chromatographic method. APS-I was demonstrated as a single peak by gel filration on Sepharose $4 \mathrm{~B}$ and by ion exchange chromatography on DEAE-Cellulose (Fig. 2, Fig. 4). APS-II also showed a single peak on Sephadex G-200 (Fig. 3).

Ultra-centrifugal analysis. Each APS dissolved in $0.2 \mathrm{M}$ sodium chloride showed a single peak on analytical centrifugation (Fig. 5).

Zone electrophoresis. APS-I and -II also seemed to be homogeneous on zone electrophoresis on glass fiber paper (Fig. 6).

Some physical properties of purified APS

Viscosity. Viscosity measurements were performed at four different concentrations of 


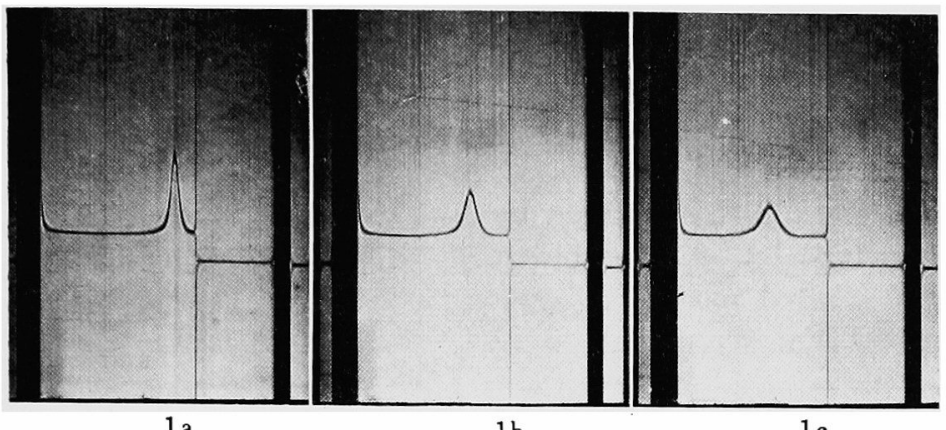

$1 \mathrm{a}$

$1 b$

1c

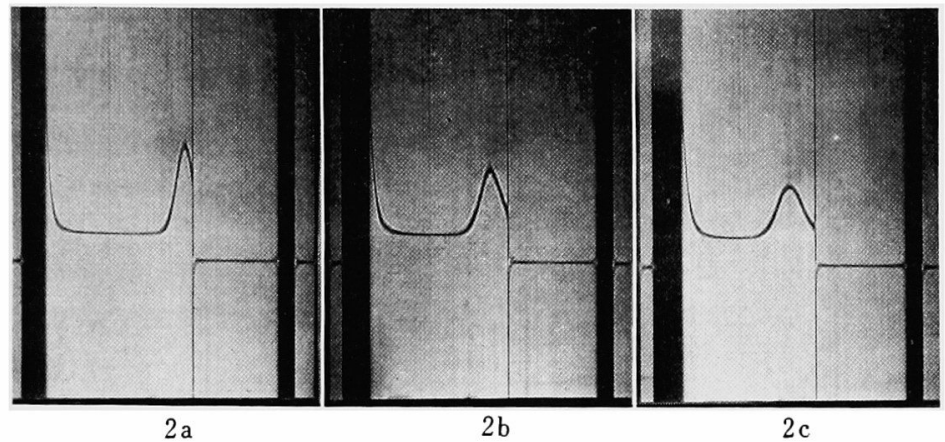

FIG. 5. Sedimentation Patterns of APS-I and -II in $0.2 \mathrm{M} \mathrm{NaCl}$.

The photographs were taken at indicated times after reaching full speed $(55,430$ rpm) at $70^{\circ}$ bar angle.

Lpper; $0.56 \%$ of APS-I solution at 20 (la), 40 (lb) and $60 \mathrm{~min}$ (1c). Lower; $1.23 \%$ of APS-II solution at $30(2 \mathrm{a}), 60(2 \mathrm{~b})$ and $90 \mathrm{~min}(2 \mathrm{c})$.

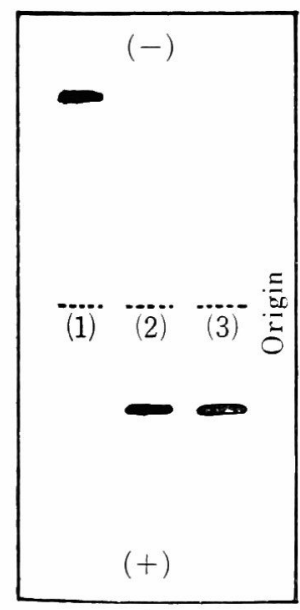

A

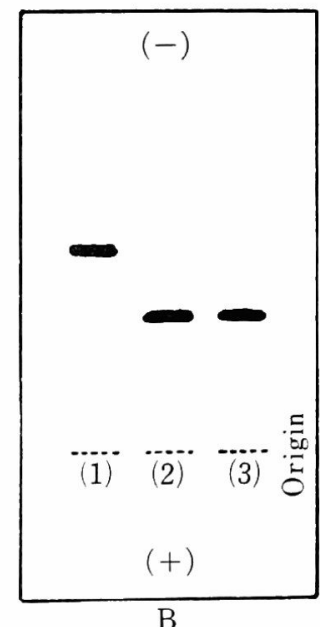

B

FIG. 6. Zone Electrophoresis of the Polysaccharides from Soy Sauce on Glass Fiber Paper.

A: Buffer, pyridine-acetate, $\mathrm{pH} 6.5 ; 20 \mathrm{~V} / \mathrm{cm} ; 3 \mathrm{hr}$. B: Buffer, $0.05 \mathrm{~m}$ borate, $\mathrm{pH} 9.2 ; 15 \mathrm{~V} / \mathrm{cm} ; 2 \mathrm{hr}$. Polysaccharide sample: (1) Neutral polysaccharide in soy sauce (2) APS-I (3) APS-II

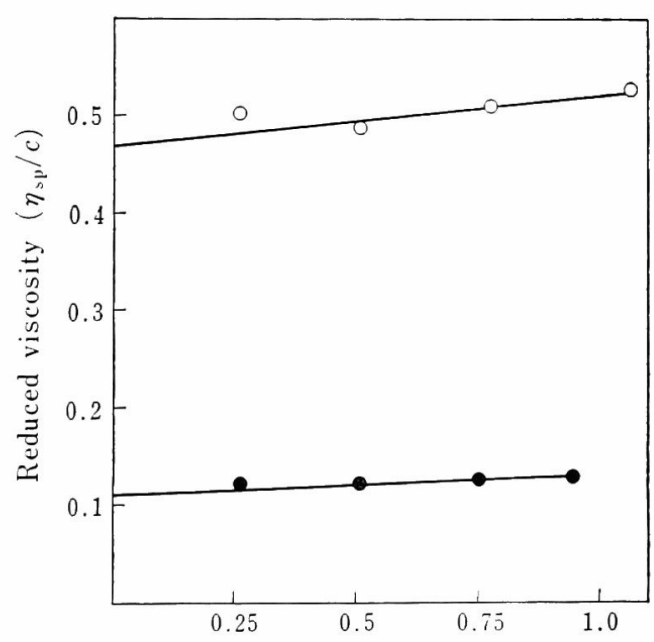

Polysaccharide concentration (\%)

EIG. 7. Concentration Dependency of Reduced Viscosity of APS-I and -II.

The intrinsic viscosity obtained; $[\eta]=0.47(\mathrm{I})$, 0.11 (II) $\mathrm{dl} / \mathrm{g}$. 
the polysaccharides at $25^{\circ} \mathrm{C}$ (Fig. 7). The values of intrinsic viscosity were obtained by extrapolation at zero concentration.

Sedimentation coefficient. $s_{20, \mathrm{w}}$ calculated by ultra-centrifugal analysis at four different concentrations were plotted against polysaccharide concentrations (Fig. 8).

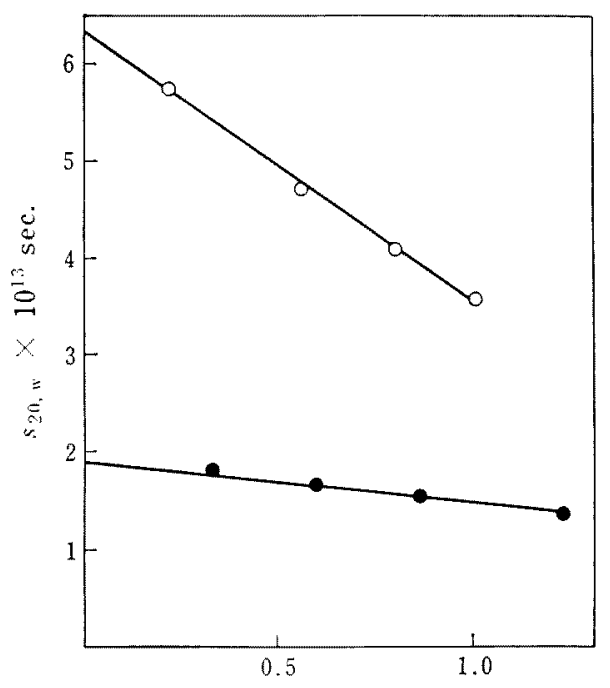

Polysaccharide concentration (\%)

FIG. 8. Cincentration Dependency of Sedimentation Coefficient of APS-I and -II.

The extrapolated value; $s_{20, \mathrm{w}}^{0}=6.35 \mathrm{~S}(\mathrm{I})$ and $1.9 \mathrm{~S}$ (II)

\section{Estimation of molecular weight}

APS-I, APS-II and standard dextrans were chromatographed on Sepharose $4 \mathrm{~B}$ and Sephadex G-200. $K d$ values of standard dextrans were plotted against molecular weights, and the molecular weights of the polysaccharides were determined from their $K d$ values (Figs. 9, 10).

Also the molecular weights were calculated from the sedimentation coefficients and the intrinsic viscosities. But, a little difference was observed between the values obtained by these two methods. Recently, some investigators used gel filtration technique for the molecular

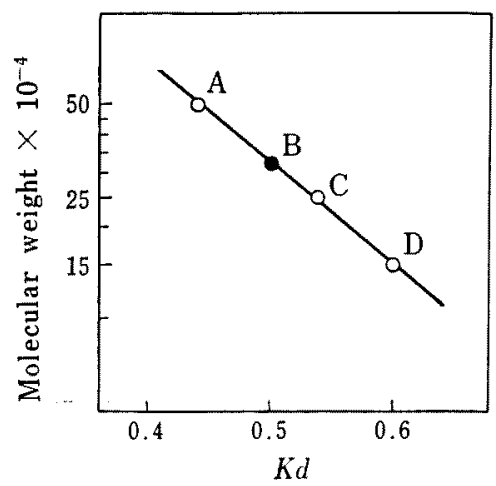

FIG. 9. Estimation of Molecular Weight of APS-I by Gel Filtration.

$1.5 \times 90 \mathrm{~cm}$ column of Sepharose $4 \mathrm{~B}$ equilibrated with $0.2 \mathrm{M} \mathrm{NaCl}$.

A; Dextran T-500; B, SPS-I; C, Dextran T-250; D, Dextran T-150.

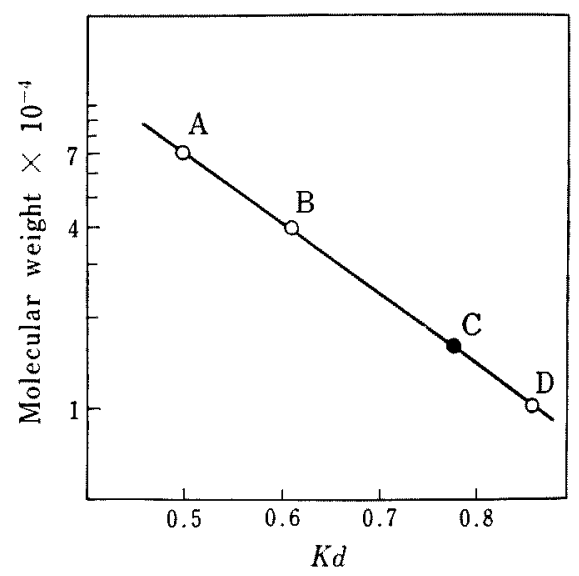

FIg. 10. Estimation of Molecular Weight of APS-II by Gel Filtration.

$1.5 \times 90 \mathrm{~cm}$ column of Sephadex G-200 equilibrated with $0.2 \mathrm{M} \mathrm{NaCl}$.

A, Dextran T-70; B; Dextran T-40; C, SPS-II; D; Dextran T-10.

weight determinations of polysaccharides. ${ }^{13-15 t}$ The other method was usually applied for globular proteins. In this paper, therefore, the molecular weights measured by gel filtration were adopted as more precise values for those acidic polysaccharides. Another reason was 
Table I. Summarized Physical Properties of THE ACIDIC POLYSACCHARIDES

\begin{tabular}{lcc} 
Property & APS-I & APS-II \\
\hline Sedimentation coefficient, $s_{z 0, w}^{0}$ & $6.35 S$ & $1.9 S$ \\
Intrinsic viscosity, $[r](\mathrm{dl} / \mathrm{g})$ & 0.47 & 0.11 \\
Partial specific volume, $\bar{V}(\mathrm{ml} / \mathrm{g})$ & 0.68 & 0.66 \\
Molecular weight & & \\
Gel filtration & 320,000 & 16,000 \\
$s_{20, N}^{0},[r]$ & 285,000 & 20,500 \\
\hline
\end{tabular}

that no knowledge on their physical structures had been obtained yet.

The physical properties of purified polysaccharides are summerized in Table I.

\section{Sugar composition of purified APS}

According to the paper chromatography, it was shown that both APS's were composed of a large amount of galacturonic acid, smaller amounts of galactose, xylose, and rhamnose, and traces of arabinose and fucose. None of the esterified methanol was detected in any polysaccharides. Sugar compositions of the polysaccharides according to colorimetric methods are shown in Table II.

TABLE II. SUGAR COMPOSITION OF SOME ACIDIC POLYSaCCHaRIDES

\begin{tabular}{|c|c|c|c|}
\hline Acidic polysaccharide & $\begin{array}{c}\text { Uronic } \\
\text { acid }^{0} \\
\left(0_{0}\right)\end{array}$ & $\begin{array}{c}\text { Pentosel } \\
(0)\end{array}$ & $\begin{array}{l}\text { Methyl- } \\
\text { pentoseb } \\
(0)\end{array}$ \\
\hline APS-I & 52.6 & 20.6 & 12.1 \\
\hline APS-II & 50.3 & 20.7 & 11.7 \\
\hline $\mathrm{HMP}^{\mathrm{a}}$ & 52.5 & 22.4 & 11.4 \\
\hline LMPE: & 51.3 & 23.3 & 9.8 \\
\hline
\end{tabular}

a) High and low molecular polysaccharides obtained by enzymatic degradation of soybean cell wall.

b) Uronic acid, pentose, and methylpentose were calculated as galacturonic acid, xylose, and rhamnose, respectively.

Examination of the acidic polysaccharides obtained by an enzymatic degradation of soybean cell wall Ten grams of pre-cooked soybean cell wall were incubated for $20 \mathrm{hr}$ at $40^{\circ} \mathrm{C}$ with
$200 \mathrm{mg}$ of the crude enzyme preparation from a koji-culture of Aspergillus sojae X-816 and with $200 \mathrm{ml}$ of $0.05 \mathrm{M}$ acetate buffer $(\mathrm{pH}$ 5.0). After the incubation, the reaction mixture were filtrated. From the filtrate, $550 \mathrm{mg}$ of crude acidic polysaccharides were prepared by ethanol precipitation and successive ion exchange chromatography on DEAE-cellulose in the same manner as in the case of soy sauce. The acidic polysaccharides were divided into two fractions by gel filtration with Sephadex G-200. The sugar composition of each fraction was investigated (Table II). Consequently, it seemed that these polysaccharides were very similar to the acidic polysaccharides in soy sauce, in the sugar compositions.

\section{DISCUSSION}

The authors previously reported about the properties of soybean cell wall polysaccharides and those enzymatic decomposition. They also suggested that acidic polysaccharides might be present in soy sauce. ${ }^{11}$ As described above, some acidic polysaccharides were actually isolated from soy sauce by the combination of an ion exchange chromatography and a gel filtration, and their physico-chemical properties were investigated. The acidic polysaccharides were composed of two types, APS-I $\left(M=320,000 ; s_{20, w}^{0}=6.35 S\right)$ and APS-II $\left(M=16,000 ; s_{20, w}^{0}=1.95\right)$. Both of them contained large amounts of galacturonic acid and rhamnose.

According to the comparison with the acidic polysaccharides prepared by an enzymatic decomposition of soybean cell wall, the acidic polysaccharides from soy sauce showed strong resemblance to those from soybean cell wall in the behavior on gel filtration and on their sugar compositions. In consequence, the authors supposed that the acidic polysaccharides in soy sauce might be originated from those in the soybean cell wall, namely pectic substances. 
Acknowledgements. The authors wish to express their sincerest thanks to Prof. M. Fujimaki of the University of Tokyo for his kind guidance and encouragement throughout this work. Thanks are also due to Mr. S. Ishii, Mr. T. Iwasa, and Dr. K. Hayashi for their valuable advices and suggestions; to Dr. H. Sugimoto, Dr. S. Sugiyama, and Dr. D. Fukushima for their helpful discussion and encouragement; and to Mrs. R. Nemoto for her technical assistance.

\section{REFERENCES}

1) T. Kikuchi, S. Ishii, D. Fukushima and T. Yokotsuka, Nippon Nogeikagaku Kaishi, 45, 228. 235 (1971).

2) M. Fukuchi, N. Hishiki, K. Mori, R. Ueda, Y. Ishigami and H. Ishikawa, Hakko Kogaku Zasshi, 47, 510 (1969).

3) M. A. Jermyn and F. A. Isherwood, Biochem. J., 44, $402(1949)$.
4) A. J. Barrett and D. H. Northcote, Biochem. J., 94, 617 (1965).

5) C. M. Wilson, Anal. Chem., 31, 1199 (1959).

6) P. Andrews, Biochem. J, 96, 595 (1965).

7) H. A. Scheraga and L. Mandelkern, J. Amer. Chem. Soc., 75, 179 (1953).

8) M. Dubois, K. A. Gilles, J. K. Hamilton, P. A. Rebers and F. Smith, Anal. Chem., 28, 350 (1956).

9) T. Bitter and H. M. Muir, Anal. Biochem., 4, 330 (1962).

10) Z. Dishe and E. Borenfreund, Biochim. Biophys. Acta, 24, 189 (1957).

11) Z. Dishe and L. B. Shettles, J. Biol. Chem., 175, 595 (1948).

12) C. Hatanaka and J. Ozawa, Nippon Nogeikagaku Kaishi, 40, 421 (1966).

13) D. M. W. Anderson, I. C. M. Dea and A.C. Munro, Carbohyd. Res., 9, 363 (1969).

14) G. Constantopoulos, A.S. Dekaban and W.R. Carroll, Anal. Biochem., 31, 59 (1969).

15) G. N. Bathgate, J. Chromatog., 47, 92 (1970). 